\title{
Post 2003 Iraq and Unhappy Reality: A Study in Sinan Antoon's The Corpse Washer
}

\author{
Rana Ali Mhoodar \\ Department of English Language, College of Education, University of Misan-Iraq
}

\begin{abstract}
This paper focuses on the existence of traumatic indications, like flashbacks and nightmares, feebleness and submission, distorted viewpoints of both present and future, alienated and disoriented people, and the robust diasporic impulse. As a genre of literature, novel has developed to be a fundamental way in revealing one's country's being destructed and increasingly annihilated of its people. Novel in Iraq has touched surrealism, nonlinearity, fragmented events, and other techniques used in narrating and documenting the unescapable reality and the situations of trauma by which the country has suffered for years and years. Characteristics of both form and content are employed by Sinan Antoon employs and of those are fragmentation, nonlinearity, and nightmares to novelize the traumatic events experienced by the Iraqi people. Analysing the extracts has suggested that traumatic experience brought about by persistent occurrence of conflicts and dictatorship have turned the Iraqi people into traumatized characters and molded their existence, identity, and ties to the place.
\end{abstract}

Keywords: Sinan Antoon, The Corpse Washer, Pos2003, Iraqi Novel, Fragmentation,

\section{INTRODUCTION}

Film makers according to Levine (2015: 265) are devoted "to achieving both aesthetic and historical accuracy." Instead of harshly criticizing the documentaries against the policies of the United States of America in Iraq, they prefer the engagement offering complicated narrative to reflect the reality on the ground. Fiction with its US experts' concerning the Iraq war can be regarded as an attempt to express the real hardships brought about by war, which are not like the envisioned hardships depicted by the media.

As it is admitted by some of these authors, their outputs are represented by to the regularly posed question concerning the feeling of being in the battlefield, as well as doing the best of effort to tell about the misfortunes of being part of a destructive and effortless kind of war.

\section{Iraqis Post-war Literary Writing}

Such literary outputs to the Iraq war, which are written in English language, track a category and perspective, which is about the situation of the troops that invaded Iraq. Of these writings, few have discussed the Iraqi people's situations as well as the Iraqi soldiers' while reacting to the war against their homeland or reacting against decades of oppression, mass destruction and tyranny. As the returning experts' descriptions of the Iraq war show their reflections of the reality of war for the invading forces, literary writing written by Iraqis offer a better opportunity to grasp the real Iraqis experiences of traumatic events. However, many Arab writers/authors have rendered writings of traumatic events as a fundamental part of the Arabic world. These writers/authors have effectively tackled the Palestine-Israel everlasting conflict, civil war at Lebanon, the great wave of Arabs' immigration to the USA, and their identity struggle. Mahmoud Darwish and Elias Khoury are shining starts in the realm of literary writing for issues of traumatic events, loss of identity, exile life, deprivation of freedom, and identity struggle for Palestinians and Lebanese. 
During Saddam Hussein's rule, Iraqi authors have witnessed an oppressive situation; set the 2003 invasion a longdesired freedom to express their insiders concerning the real life in Iraq then. A range of subjects are covered by their writings, and such writings are varied from the different kinds of mishaps suffered by the Iraqis for almost 35 years of sever rule before the 2003 invasion to the chaotic situation that came after it to touch on the robust diasporic impulse of the citizens and the identity struggle of those living or returning from exile.

\section{Trauma Literature and Speaking of the Unspeakable}

Shoshana Felman (2002) states that "the twentieth century can be defined as a century of trauma," (p.171), where the events of tragedy and violence have pervaded during that century. The variance and abundance in literature has increased when writers attempt to portray the way history has abandoned the uncovering of feelings, thoughts and emotions.

To investigate into the unknown wounds caused by violent and tragic events is the interest of trauma literature. It is the way trauma speaks the unspeakable and remember the fragmented bodies. Trauma literature through its aim as Vickory (2002) remarks that trauma literature, "is to help readers to access traumatic experience," particularly through the use of fictional trauma narrative (p. 1)

Cathy Caruth (1966) emphasizes that literature is a nonpareil realm for representing traumatic experience. Literature, she argues, enables us "to bear witness to events that cannot be completely known and opens our ears to experiences that might have otherwise remained unspoken and unheard” (p. 2). Literature becomes a site for a belated enactment and witnessing of what can be referred to as the "unclaimed moment" of trauma (p. 3). Following Freud, Caruth argues that the language of trauma is inherently literary, "because literature, like psychoanalysis, is interested in the complex relation between knowing and not knowing” (p. 3). Caruth, further, suggests that this epistemological crisis in trauma functions as an interface between psychoanalysis and literary language: "it is at the specific point at which knowing and not knowing intersect that the language of literature and psychoanalytic theory of traumatic experience precisely meet”(p. 3).

\section{Trauma and Traumatic Stress Disorders}

Trauma and its sequences have taken Freud's consideration to continuous pattern that is characterized with victims experiencing anguish and such an anguish is caused by as a result of coming back from the WWI. This pattern is resembled by the illness of those who have gone through lifethreatening incidents, which he called “traumatic neurosis" (Freud, 1961.p. 6). Pierre Janet (1859-1947), among the researchers who attempted to create a set of common signs that can be caused by traumatic experiences to those involved in these experiences. The term "Post-traumatic syndrome" (Herman, 1997.p. 45) is employed as a reference to the mental suffering or "the series of grave physical and motor symptoms" which comes after an individual encounters a calamitous state of affairs or a "shocking incident" (Caruth, 1996.p.16). Post-Traumatic Stress Disorder (PTSD) is expressed as "reflects the direct imposition on the mind of the unavoidable reality of horrific events, the taking over of the mind, physically and neurobiologically, by an event that it cannot control" (Caruth: 1996.p.58).This definition clarifies the point in which the most destructive influence can be brought about due to external violence towards the human inner self.

As compared by Herman (1997) that the abandoned traumatic victims to animals who "freeze" upon being attacked by an influential predator. However, humans' case is continuously defeated, as it can be connected to the awareness than actions: "These alterations of consciousness are at the heart of constriction or numbing [...]. 
Sometimes situations of inescapable danger may evoke not only terror and rage but also, paradoxically, a state of detached calm, in which terror, rage, and pain dissolve (p.42). such circle of indications clarifies all the alienated person resulting, as well as inner deadness, and the deficiency of balanced victims whose life events become "disconnected from their ordinary meanings [...] and [...] lose its quality of ordinary reality" (Ibid.43). When "indifference, emotional detachment, and profound passivity" are combined, they produce a lack of initiatives for the coming individual enhancement in traumatized and can assist them to lose faith and familial and friendship ties with family and friends. Such shifts in the way the victimized practice as part of their way of living, are regarded as the reason of the traumatized individuals' failure to cope with their lives. This also causes larger suicidal attempts come after being traumatized.

\section{METHODOLOGY}

In this paper, the methodology that is followed can be shown as follows: presenting an introduction of trauma, posttraumatic stress disorder, origins, characteristics as well as the novel under investigation 'The Corpse Washer' and so on. Then, the term trauma of during the 2003 Iraq War that adds to the emergence of the term trauma, characteristics as well as some insights concerning the problem of traumatized people and their fragmented selves as well. After finishing the concerns of trauma, its negative impacts are tackled and discussed in the novel itself. To be mentioned as well, the consequences of the 2003 Iraq War find space in this article as depicted by the author Sinan Antoon. As trauma and the like are emphasized here, a review of recent critiques by some writers of the trauma and traumatized people as presented by the pioneers of the Trauma Theory such as Cathy Caruth and Herman, followed by a brief discussion on war and violence in Iraq after 2003. Through this article, it is aimed to figure out some of the logical reasons that led to the writing of such a wonderful piece of art.

\section{The Corpse Washer: A “Trauma Novel”}

When Sinan Antoon's novel The Corpse Washer is read, it gives the feeling that it can be categorized as 'a trauma novel'. Such a term according to (Balaev, 2008) denotes to a fictional piece of art by which an intensity of fear is conveyed whether individually or collectively. To called the novel under such a term is attributed to two reasons. The first one is taken form an individual sense, which means that a traumatic narrative is experienced by the characters of that narrative (i.e. novel and so on). While the second reason is much broader as it takes a historical attribution, which is the cultural product of a country that is caused by a traumatic history. Within The Corpse Washer, a redefinition is offered by Antoon by which the trauma of war as it its violent outcomes are exposed psychologically and emotionally. Multiple facets of violence are explored in Iraq; as such violence appears in the street, made to the bodies of the victims. It also shatters the victimized experiences of the Iraqis' minds and hearts. Through the novel, the author demonstrates his condemnation against the dismays of war, and the besieged violence against innocent people.

In Iraq, the year 2003 witnessed the military occupation and the release of violence on bases of sectarianism. War brings about destruction and misery and turns city life into a graveyard, and the rivers are filled with dead bodies which have become food for the inanimate creatures. In this regard, Jawad poses the question for asks himself saying who cares for the dead, since death deserts the corpses to the living?”. In this situation, Jawad discovers that her himself is forced to carry on the career of his dead father. Jawad through his life of traumatized experiences, his family's and friends' disappearance and the haunting nightmares, has frequently made him become a character of reality; 
however leave him with his increased desperate and loneliness.

Jawad's individual and collective traumatic experiences are emphasized by Antoon to represent the emerging self-fear, alienated and isolated self that can be experienced by a traumatized individual after going through a traumatic event. Here, Jawad signifies Kai Erikson's detects of a traumatized person who is totally occupied, and embraced by trauma. According to Erikson (1995), trauma is the feature that dominates the interior landscape of its victims; it "possesses" them and "threatens to drain 'them' and leave 'them' empty" (p.183).

The Corpse Washer is a display of Caruth's standpoint of trauma as "wound." Noting Freud's view of trauma as "wound of the mind", and through the insistence of Caruth (1996) that trauma involves a double wound, (i.e. the wound of the original catastrophe and that of its recollection). Then, Caruth is of the argument that:

"trauma seems to be much more than pathology, or the simple illness of a wounded psyche, it is always the story of a wound that cries out, that addresses us in the attempt to tell us of a reality or truth that is not otherwise available” (p. 4).

This means that, without trauma, the wound would be "unspoken or unrecognized.” As Caruth (1996) put it, yet, "the originating wound is unspeakable, even unrecognizable, at the moment it is experienced. It is not available to consciousness until it imposes itself again repeatedly in the nightmares and repetitive actions of the survivors" (p. 4).

\section{Symptom of War Trauma: Nightmares}

Throughout the novel, the nightmarish episodes are well-depicted by Antoon to highlight the lasting trauma agonized by Jawad. As a war trauma, nightmares have been noticeable indications of it. The imagery of dream of the nightmare is employed for comprehending the issues that emerge out of the traumatic experience.
Jawad's nightmares appear to be a recurrent motif in the novel. In this regard, Kai Erikson (1995) observes that "trauma involves a continual reliving of some wounding experience in daydreams and nightmares, flashback and hallucinations and in a compulsive seeking out of similar circumstances" (p. 184). It appears as whether the violent incidents are happening during the day and they were not enough, and therefore, Jawad is devastated by such nightmares that have not appeared as dreams but as reality, with lines such as "I start to suffocate, then bolt awake"(CW. 122).

\section{The Effectiveness of Iraqi Novels}

Iraqi novels about war and its consequences show them as if they are engaging with reality; being rooted in the human suffering that is caused by war. The literature of the Iraqi novels is very significant in that it shows the Iraqi writers in a state of ability to regard the outcome the debris brought about by America's war in Iraq. The emphasis of their writings is on agonies of real persons that are caused by political violence; and to show such agonies is in such a way to represent both the individual and the collective suffering of the Iraqis. Many truths are grasped by Iraqi novels as they seek to discover the lost meaning they surpass through personal experience and are about the over whelming outcomes of war. Sinan Antoon in an interview, he approves that these years of violence are followed by two wars in Iraq, in the US press the concern lies in writing of the experts. Here, in these fictions, Antoon claims that the American experts are also victimized by the Iraqi war as well as the Iraqi civilians disappear (Forbes, 2015).

Alan Sinfield (2004) in Literature, Politics and Culture in Post-war Britain enhances the reality that "Literature is an institutional arrangement we have made to dignify some writing at the expense of other" (31). Sinfield believes that literature is a cultural apparatus and that any culture will value some texts more highly than 
others. He states that literature concerns the authority and of any work of art to be accepted, which is to be judged to attain its voice in discourse with certain remarks of importance. Thus, a work of art may come to seen as a literary work or it may be depending on the contexts that regards it to be interpreted. Here, Sinfield repeats that "The literary as it is deployed in our culture is less a property of texts than a way of reading and placing texts” (p.33).

\section{Reforming the Concept of Cruelty in Sinan Antoon The Corpse Washer (2013)}

The scenes of cruelty are represented in The Corpse Washer through reforming this concept by shedding light of the everyday sights of violence in the capital city of Baghdad. Such scenes are themes of malevolence, misery, and the tearing of bodies. Sinan Antoon's The Corpse Washer (2013) shows the way its protagonist comes to terms with trauma as he endlessly comes across his personal encounters with death as a corpse washer. Obviously, The Corpse Washer was written in Arabic by Sinan Antoon in 2012, an exiled Baghdad-born Christian who lives is New York-America. Then this novel was personally translated into English in 2013 by the author. This novel narrates Jawad Salim's story, who is an Iraqi Shiite artist and was turned into a corpse washer against unwillingly. As readers, we are presented into a daily personal story of the death corpses that are piled up in Baghdad due to the US occupation to Iraq and the sectarianism that is urged between the two main castes in Iraq (i.e. Shiite and Sunnis).

Jawad's wish was to be a sculptor rather than a corpse washer. However, during the days of occupation, the political and economic conditions followed by the setting free of violence, hostility and sectarianism that broke out the sectarian war between Shiite and Sunnis. Such war caused the emergence of dead corpses and joblessness in Iraq. Such violent events confirm the fact that Jawad did not make his dream come true and return to corpse washing, which is his unwanted career. Jawad's personal experiences, offer a comprehensive view of the war caused by sectarian issues and the daily conflict of the Iraqi people with violent incidents and deaths.

As a daily witness of deaths, Jawad is the receiver of death. The dense causes that are perpetrated in Baghdad requires Jawad's return to his father's undesirable career of corpse washing. Since Jawad is accustomed to the daily scenes of sectarian war, he gives an account to his career in the following words:

"If death is a post man, then I receive his letters every day. I am the one who opens carefully the bloodied and torn envelopes. I am the one who washes them, whore moves the stamps of death and dries and perfumes

them, mumbling what I don't entirely believe in. Then I wrap them carefully in white so they may reach the final reader the grave" (CW. 3).

In The Corpse Washer, terms such as misery, malevolence, and wound culture characterize Jawad's shocking story which like his heart is "full of death" (CW. 135). Through the narration, we are told that the novel is shaped by death. A career of corpse-washing becomes the routine job for Jawad. Both of the traumatic events and the dead corpses that are washed, shrouded and coffined by him, place torture upon his soul especially during night. Such a torture causes him sleeplessness and dreadful nightmares. In a comparison made by Jawad, in which he looks at himself as a pomegranate tree that grows just outside the Mghasyl (washroom). This is because the tree is watered $b$ the water of death budding and blossoming.

Jawad says "all my branches have been cut, broken and buried with the dead. My heart has become a shrivelled pomegranate beating with death and falling every second into a bottomless pit" (CW. 160). In a similar way, the roots of the pomegranate tree were there in the washroom in the depth of hell. Antoon's 
novel is an outstanding adaptation of Kristeva's conception of abjection in which the abject has to encounter the protagonist when he enters the Mghasyl (washing room) to witness the dead corpses. Jawad through his life is both drawn to and rejected by the abject. Even his feelings of anxiety and sickness are the psychological and the biological confession that the abject is present. Due to the effect of his many encounters, he becomes a very powerful individual though he is overwhelmed.

\section{The Role of Media in The Corpse Washer}

The media in The Corpse Washer, is shown to function as an imitation of the violent scenes. In the novel, TV serves to show the violent sectarianism between the Sunnis and Shias who are exterminating each other and to demonstrate the scale of the destruction of Iraq. TV broadcasted the Iraqi tragic situation during and after the US occupation. As Jawad witnesses "eventually, the dish become our only window through which we could see the world and the extent of our own devastation, which multiplied day after day" (CW. 88). It is interesting that The Corpse Washer exhibits the way the TV was employed as a tool of communication the groups of gangs to threaten, impart fear and terrify the civilians through broadcasting the daily spectacle of people's beheaded live on TV. As intensified by Antoon, the media spectacle horrifies people as one day the protagonist moves through the TV channels to find something that might offer a sort of relief for his sleeplessness. However, he finds nothing by only one channel where a dreadful scene of dreadful scene of beheading is being broadcasted:

"Five hooded men stand around a sixth, who kneels and wears an orange work suit. A black bag shrouds his head. Four men hold their weapons while their leader reads the execution verdict to the kneeling prisoner." After tilting the head of the prisoner with a single blow with his sword, Jawad recalls I feel nauseated and turn off the TV, but blood flows from the screen, covering everything around me in blood”. (CW. 54)

\section{Sinan Antoon's The Corpse Washer}

In this paper, the novel under discussion is Sinan Antoon's 'The Corpse Washer', which tackles both the pre-war and post-war Iraq. It aims to showing what consequences can be caused by the nonstopped war and long years of tyranny on the country. A time span from 1988-2006 what the novel covers to touch upon the Gulf War, the siege on Iraq for being invading Kuwait in 1990, Iraq War of 2003, and the following civil war. The depiction of Jawad calls "nightmare[s] of wakefulness" are different as they begin as a shared-narrative to awaken the world. For example, Jawad has dreamt to stand in a long queue to have his new passport issued after being banned for a rather long time due to finding out communist connections of his uncle. Joining a queue by a suicide bomber to cause a huge explosion, where civilians' bodies are scattered here and there and Jawad's face is covered with blood, but he is amazed that his body is still undamaged:

Jawad says "Iheaded to the Mghasyl and opened the faucet to wash myself. I lay down on the washing deck to die, but instead I awoke" (CW, 140). The critic Grant Barber (2013) explains that with such a nightmare, Jawad departs the reader dreaming with reality, the ordinary and the unreal. Again, Jawad sees his father in the Mghasyl, however, it totally dark and they need candles because, this is the underworld. Corpses are everywhere and bodies are shattered here and there. This chaos needs to be washed and shrouded. Therefore, Jawad poses a question for father whether they are alive or dead, yet his father's answer is in vain. After that, Jawad wakes up and finds the candle next to his bed "choking and about to give out" (CW. 146). He is unsure whether he waking or dreaming because in his dream, both of the real and underworld look utterly similar.

The reader is motivated by the abundance of the nightmares in The Corpse 
Washer to make sense of the ostensible and distinct contents of such nightmares to find their portraying of a reality that is both intolerable and inescapable. In general, indicators such as repeated flashbacks, recurring nightmares, and repetition are some of the main factors that wellrepresenting trauma, if we take into account that early stages of trauma: hyper-arousal and intrusion.

Trauma as a fundamental aspect in literary narratives, it involves repetitions, which are revealed through the repeated occurrence of specific words and phrases by which new meaning and significance would be acquired. Repetition also adds to a fragmented and nonlinear novel, where Jawad's narrative continuously moves from the present to the past events, to refer to many events between the 1980 and 2006. In the first nightmare-chapter, Jawad appears in adulthood as working in a corpse washer place after his father has died in2003. The next chapter moves the narration back to the early 1980s, in which Jawad attends his mother to his father's work place known as the Mghasyl. Then the narration moves much further to 1988 to offer an elucidated description of Ameer's death, Jawad's eldest brother, in the battels took pace in alFawcity during the Iraqi-Iranian War. Death has come to be acknowledged as the hallmark of Jawad's family, is "about to declare its presence once again, but with a cruelty and force that would tattoo itself on the heart of Jawad's father, who wept like a child after losing his favorite son" (CW. 17).

Here, Antoon's reference to certain and real incidents to concentrates on the difference between what is illusionary and what is real. The analysis of Antoon's The Corpse Washer from a trauma theory viewpoint demonstrates that the fictional characters' as well as their real-life in the context of Iraq separated views on living in the present and the future. Even the merging boundaries between life-death, and the growing diasporic impulse all contribute to Iraqi people's protracted trauma. Antoon's portrayal well interprets the Iraqi situation socially, politically, and economically.

\section{CONCLUSION}

In conclusion, after having examined the literary text The Corpse Washer. It expresses and contemplates through public anxiety. The tone of the novels is sad, gloomy and melancholic. It proved that its episodes are fresh in the memories of many writers and readers. As cultural reflection, this novel tends to assume that instead of creating a democratic pro-American Iraq, an authoritarian and sectarian country has been created by the war with a great deal of antiwestern attitude. This means that, this novel expresses the real situation of the Iraq War and its effects that spread the cultural consciousness of the period. The Corpse Washer as a trauma novel delivers the lifethreatening loss and suffering both individually and collectively. The protagonist, Jawad, in addition to most of the characters in the novel have become traumatized by the war. Antoon choice of the hard career of corpse washing enforces us to encounter all of Iraqi people's traumas.

As a final conclusion. The Corpse Washer expresses the story of a carrying wound, that both demonstrates a telling and retelling of the Iraqis' traumas. Iraqis have been victimized by violent incidents and tragedies of murdering to witness the destructive picture of their country. Various forms of both individual and collective traumas are yet to be continually experienced by Iraqis, while their daily-life is loaded with traumatic experiences, oppression and violence. The continuous resistance of the Iraqis shows their attempt to make art as ways to cope with misery and to heal traumatic experiences. A destruction is not the mere function of trauma, yet it creates. Therefore, such a creation of trauma lies an act of creation, to bind together and to water trees that existed to witnesses the life within destruction and grief. 


\section{Acknowledgement: None}

\section{Conflict of Interest: None}

\section{Source of Funding: None}

\section{REFERENCES}

1. Antoon, S. (2014). The Corpse washer. London: Yale University Press.

2. Balaev, M. (2008) Trends in Literary Trauma Theory. Mosaic. 41 (2).

3. Caruth, C. (1996) Unclaimed experience: Trauma, narrative, and history. Baltimore, MD: The Johns Hopkins University Press.

4. Caruth, Cathy. Unclaimed Experience: Trauma, Narrative, and History. Baltimore: Johns Hopkins University Press, 1996. Print.

5. Erikson, K. (1995). Notes on trauma and community. In Caruth, Cathy. Trauma: Explorations in memory (pp. 183-199). Baltimore, MD: The Johns Hopkins University Press.

6. Felman, Sh. (2002). The Juridical unconscious: Trials and traumas in the twentieth century. Massachusetts: Harvard University Press.
7. Forbes, M. (2015) Iraqi Writer Sinan Antoon on his Novel. The National. 14 May.

8. Freud, Sigmund. Beyond the Pleasure Principle. Trans. James Strachey. New York: W. W. Norton \& Company INC, 1961. Print.

9. Herman, Judith L. Trauma and Recovery: The Aftermath of Violence--from Domestic Abuse to Political Terror. New York: Basic Books, 1997. Print.

10. Levine, M., (2015) About Baghdad. Radical History Review 95 (2006): 262-267. Academic Search Complete. Web. 9 Sept. 2015.

11. Sinfield, A. (2004) Literature, Politics, and Culture in Postwar Britain. London: Continuum, Print.

12. Vickroy, L. (2002). Trauma and survival in contemporary fiction. Charlottesville: University of Virginia Press.

How to cite this article: Rana Ali Mhoodar. Post 2003 Iraq and unhappy reality: a study in Sinan Antoon's The Corpse Washer. Galore International Journal of Applied Sciences \& Humanities. 2021; 5(4): 37-44. DOI: https:// doi.org/10.52403/gijash.20211007 